\title{
Radiographic study of the distribution of maxillary intraosseous vascular canal in Koreans
}

\author{
JuHyon Lee ${ }^{1}$, Nara Kang ${ }^{2}$, Young-Mi Moon ${ }^{3}$ and Eun-Kyoung Pang ${ }^{4^{*}}$
}

\begin{abstract}
Background: This study aimed to investigate the distribution and prevalence of intraosseous loop (anastomosis between posterior superior alveolar artery and infraorbital artery) in Koreans detected on computed tomography (CT) images taken prior to sinus augmentation surgery.

Methods: From the 177 patients who underwent sinus augmentation with lateral approach at Ewha Womans University Department of Implant Dentistry, $284 \mathrm{CT}$ scans were evaluated. The canal height (CH), ridge height (RH), and canal height from the sinus floor (CHS) were measured on para-axial views at the first premolar, first molar, and second molar. The horizontal positions of the bony canals in the lateral wall were also classified. One-way analysis of variance (ANOVA) and $t$ test were used to estimate the statistical differences $(p<0.05)$.

Results: The intraosseous loops were detected in 92 CT scans (32\%). The mean vertical height of the bony canals from the alveolar crest $(\mathrm{CH})$ was $23.45 \pm 2.81,15.92 \pm 2.65$, and $16.61 \pm 2.92 \mathrm{~mm}$ at the second premolar, first molar, and second molar, respectively. In the horizontal positions of the bony canals, intraosseous type was the most predominant. The canal heights more than $15 \mathrm{~mm}$ and less than $17 \mathrm{~mm}$ were most prevalent (33.7 \%) and those under $13 \mathrm{~mm}$ were $12.0 \%$.

Conclusions: The radiographic findings in this study could be used to decide the lateral osteotomy line avoiding potential vascular complication. However, only one third of the canals could be detected in CT scans; a precaution should be taken for the possibility of severe bleeding during lateral osteotomy.
\end{abstract}

Keywords: Maxillary artery, Posterior superior alveolar artery, Sinus augmentation

\section{Background}

Sinus augmentation with lateral osteotomy is a predictable surgical technique that allows successful placement of dental implants to patients with extremely atrophic posterior maxilla. Despite the high level of safety and predictability [1-3], severe vascular complications may occur during lateral osteotomy as a result of arterial injury $[4,5]$. Therefore, knowledge of the arterial supply of the maxillary sinus region is crucial to avoid untoward complications [6, 7].

The arterial supply of the maxilla originates from the posterior superior alveolar artery (PSAA) and infraorbital

\footnotetext{
* Correspondence: ekpang@ewha.ac.kr

${ }^{4}$ Department of Periodontology, Graduate School of Medicine, Ewha Womans University, 1071, Anyangcheon-ro, Yangcheon-gu, Seoul 158-710, South Korea

Full list of author information is available at the end of the article
}

artery (IOA). PSAA is the first branch of the third portion of the maxillary artery (MA) and usually arises just before the MA enters the pterygopalatine fossa [8]. PSAA divides into intraosseous branch (IObr) and extraosseous branch (EObr) before entering the posterior superior alveolar foramen. Each branch forms an anastomosis with IOA and creates intraosseous loop and extraosseous loop [7, 9].

The IOA frequently arises from a common trunk with the PSAA and runs anteriorly along the roof of the maxillary sinus (orbital floor). Within the orbit, it gives rise to muscular branches as well as the anterior superior alveolar arteries, which forms an anastomosis with the PSAA [7-11].

The intraosseous loop, an anastomosis between the IObr of the PSAA and IOA, was found in $100 \%$ of anatomic specimens at the lateral antral wall, $18.9 \pm 2.82 \mathrm{~mm}$

\section{实 Springer}




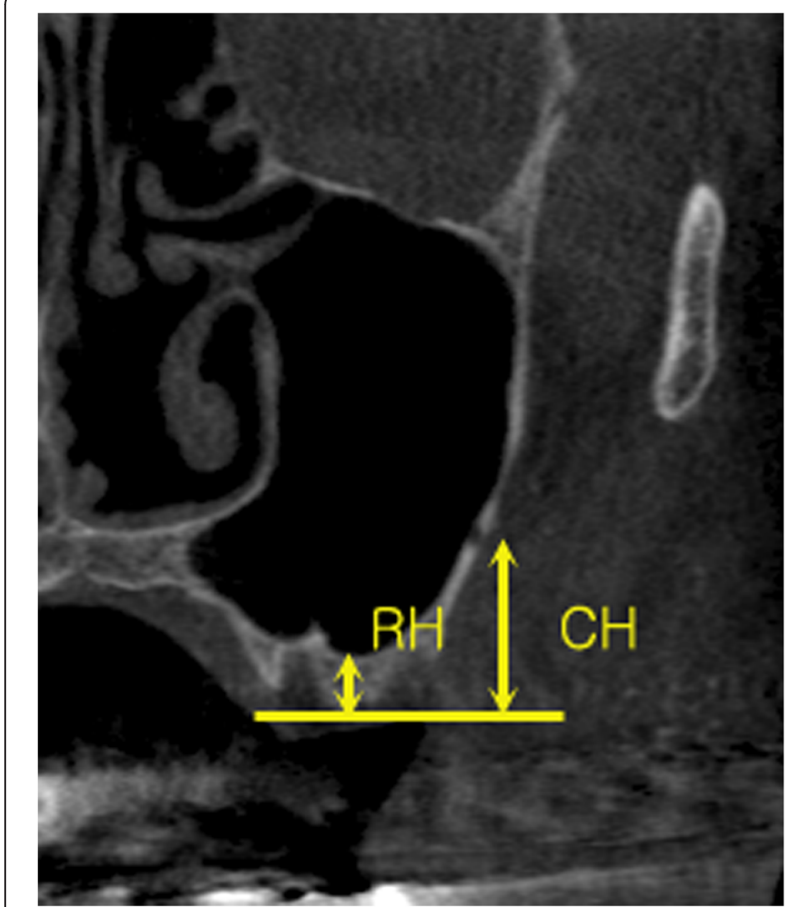

Fig. 1 The vertical position of the bony canals according to the tooth region on para-axial sinus $C T$ scan. $C H$ (canal height), distance between alveolar crest and inferior border of the canal; $R H$ (ridge height), distance between alveolar crest and sinus floor; CHS (canal height from the sinus); $\mathrm{CH}-\mathrm{RH}$

from the crestal margin [7, 9]. Elian et al. examined 50 computed tomography (CT) scans of the maxillary sinus from 625 patients and detected the bony canal (intraosseous loop) in $53 \%$ of cases [12].

Owing to its location, the intraosseous loop has the potential to cause bleeding during lateral window osteotomies $[7,9,11,12]$. Thus, it is clinically important to detect the intrabony course of the vessels for planning the proper osteotomy line to avoid damage to the vessels and to maintain perfusion of the entire bone segment [9]. However, few studies of the distribution of the intraosseous loop have been done, with none involving Koreans. The purpose of
Table 1 The vertical position of the bony canals according to the tooth region (mean $\pm \mathrm{SD}, \mathrm{mm}$ )

\begin{tabular}{llll}
\hline Tooth region & 2nd premolar & 1st molar & 2nd molar \\
\hline Identified/investigated & 2/152 (1.3\%) & $44 / 264(16.7 \%)$ & $86 / 247(34.8 \%)$ \\
$\mathrm{CH}$ & $23.45( \pm 2.81)$ & $15.92( \pm 2.65)$ & $16.61( \pm 2.92)$ \\
$\mathrm{RH}$ & $17.56( \pm 3.30)$ & $4.19( \pm 2.15)$ & $4.21( \pm 1.86)$ \\
$\mathrm{CHS}$ & $5.89( \pm 6.11)$ & $11.83( \pm 3.16)$ & $12.21( \pm 2.87)$ \\
\hline
\end{tabular}

$\mathrm{CH}$ canal height (distance between alveolar crest and inferior border of the canal), $R H$ ridge height (distance between alveolar crest and sinus floor), CHS canal height from sinus (CH-RH), G1 extrasinusal, G2 intraosseous, G3 intrasinusal

this study was to investigate the distribution and the prevalence of the intraosseous loop in Koreans detected on CT images taken prior to sinus augmentation surgery.

\section{Methods}

This study was approved by the Ewha Womans University *:* Hospital IRB (EUMC. 2014-08-009), and all participants signed an informed consent agreement.

\section{Materials}

CT images from 177 patients (284 scans) who underwent sinus augmentation with a lateral approach at the Department of Implant Dentistry, Ewha Womans University from January 2002 to December 2008 were evaluated. In case of bilateral sinus augmentations, each sinus was counted separately. In CT images, only maxillary para-axial images were included (patients who did not have para-axial reconstruction were excluded). The axial cuts at $1-\mathrm{mm}$ intervals were reconstructed into 3-mm cross sections (para-axial). Of 177 patients and 284 sinus CT scans, 68 (109 scans) were women and 109 (175 scans) were men; age ranged from 33 to 78 years (mean 55.9 years). Sixty (21\%) of the cases were fully edentulous and 224 (79\%) were partially edentulous. The right and left sinuses comprised 138 (51.4\%) and $146(48.6 \%)$ cases, respectively.

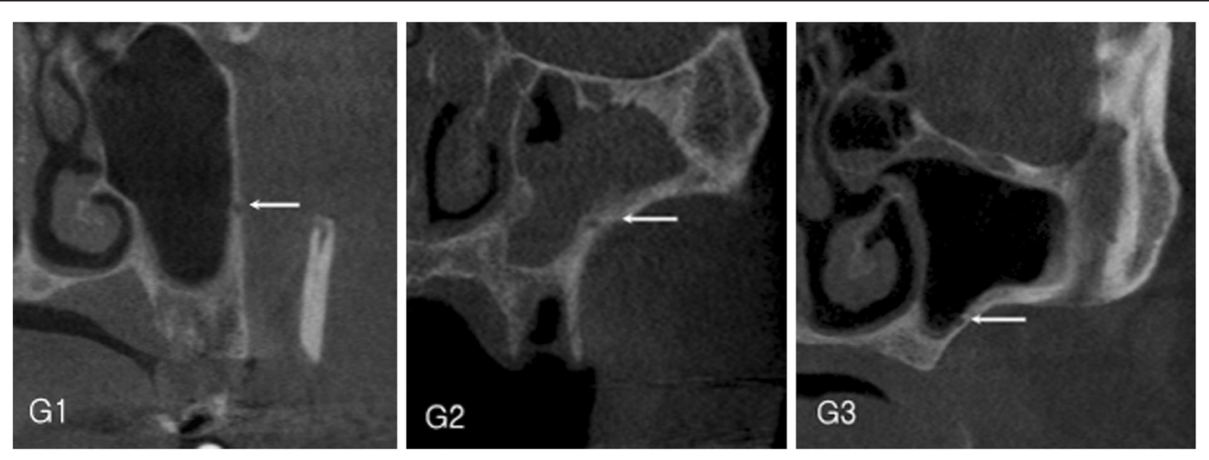

Fig. 2 The horizontal position of the bony canals. G1 extrasinusal, G2 intraosseous, G3 intrasinusal 


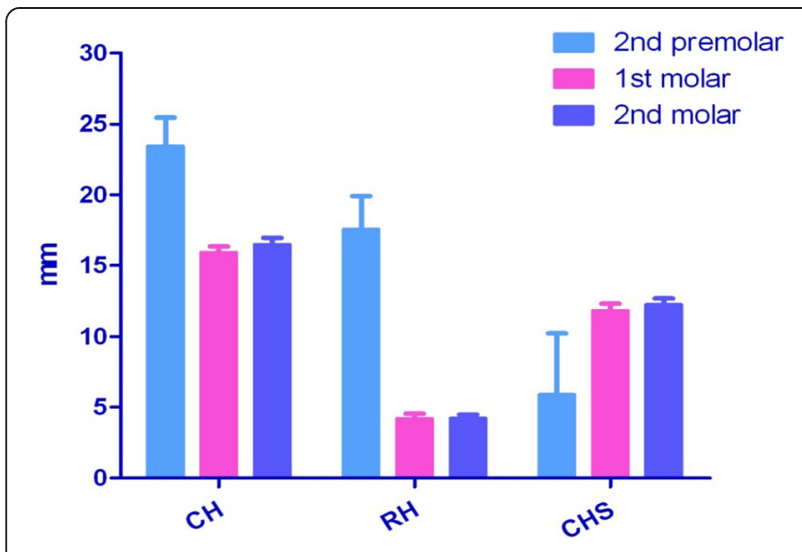

Fig. 3 The vertical position of canals according to the tooth region

\section{Methods}

Para-axial CT images were evaluated for the presence of a bony canal of the intraosseous loop in the lateral sinus wall. The canal height $(\mathrm{CH})$ and ridge height $(\mathrm{RH})$ were measured on para-axial cut using a digital caliper. $\mathrm{CH}$ defined a vertical distance from the alveolar crest to the inferior border of the canal. $\mathrm{CH}$ from the sinus ( $\mathrm{CHS}$ ) was calculated by subtraction of $\mathrm{RH}$ from $\mathrm{CH}$. $\mathrm{CH}$ was measured at each tooth position from the first premolar to the second molar (Fig. 1). The horizontal position of the bony canals in the lateral wall mesiodistally from the sinus was classified into three categories: G1, in which the canal bulged towards outside of the wall (extrasinusal); G2, with the canal embedded in the sinus wall (intraossoeous); and G3, in which the canal bulged towards inside of the wall (intrasinusal) (Fig. 2).

\section{Statistical analysis}

The measured values according to the tooth region and age were analyzed by one-way analysis of variance (ANOVA), and those according to the gender, edentulous/partial edentulous, and right/left were analyzed with $t$ test $(p<0.05)$.

\section{Results}

Two hundred eighty-four CT images were examined. The bony canal of the intraosseous loop was identified in 92 images (32\%). Concerning the vertical canal position according to the tooth region, the canal was observed to run most inferiorly from the alveolar crest at the first molar. $\mathrm{CH}$ from the sinus floor increased as the canal

Table 2 The horizontal position of the bony canals according to the tooth region

\begin{tabular}{lllll}
\hline Tooth region & Number & G1 & G2 & G3 \\
\hline 2nd premolar & 2 & $2(100 \%)$ & - & - \\
1st molar & 44 & $8(18.18 \%)$ & $34(77.27 \%)$ & $2(4.55 \%)$ \\
2nd molar & 86 & - & $75(87.21 \%)$ & $11(12.79 \%)$ \\
\hline
\end{tabular}

Table 3 Canal height according to age (mean \pm SD, mm)

\begin{tabular}{llllll}
\hline Age & $30 \mathrm{~s}$ & $40 \mathrm{~s}$ & $50 \mathrm{~s}$ & $60 \mathrm{~s}$ & $70 \mathrm{~s}$ \\
\hline $\begin{array}{l}\text { Identified/ } \\
\text { investigated }\end{array}$ & $6 / 18$ & $17 / 61$ & $36 / 86$ & $25 / 95$ & $8 / 24$ \\
$\mathrm{CH}$ & & & & & \\
& 18.06 & 15.48 & 16.49 & 16.45 & 16.75 \\
& $( \pm 4.11)$ & $( \pm 3.01)$ & $( \pm 2.87)$ & $( \pm 3.51)$ & $( \pm 2.82)$ \\
\hline
\end{tabular}

passed the posterior region (Table 1, Fig. 3). No significant differences were evident among the measured values according to the tooth region. The G2 (intraosseous) type of horizontal canal position was the most predominant in the lateral wall in the first molar and second molar regions (Table 2). The measured $\mathrm{CH}$ and $\mathrm{RH}$ values and calculated CHS values according to age, gender, edentulism, and right/left side are summarized in Tables 3 and 4. There were no statistical significances between the groups. CHs exceeding $15 \mathrm{~mm}$ and less than $17 \mathrm{~mm}$ were most prevalent (33.7\%), followed by $\mathrm{CH}$ over $19 \mathrm{~mm}$ (18.5\%) and $\mathrm{CH}$ under $13 \mathrm{~mm}$ (12.0\%) (Table 5).

\section{Discussion}

A bony canal of the intraosseous loop at the lateral wall was presently identified in $32 \%$ of the examined CT images. The mean canal height was $23.45 \pm 2.81,15.92 \pm$ 2.65 , and $16.61 \pm 2.92 \mathrm{~mm}$ at the second premolar, first molar, and second molar, respectively. The determined mean heights between the canal and alveolar crest of the particular tooth area was shorter than $50 \%$ of those previously reported in radiographic studies $[12,13]$. The reconstruction of CT images in the $3-\mathrm{mm}$ interval paraaxial cut cannot be ruled out as the reason for the shorter prevalence because the $\mathrm{CT}$ images were reconstructed from 1-mm interval para-axial cuts in other studies.

In a cadaveric study, the intraosseous loop was always found at the lateral wall of the anatomic specimens while the extraosseous loop was found only in $44.4 \%$ near the periosteum at the level of $22.75 \pm 1.49 \mathrm{~mm}$ from the alveolar crest $[7,9]$. In a Korean anatomic study, the intraosseous loop was also found in all examined cadavers; the average external diameter was $0.9 \pm 0.3 \mathrm{~mm}$ and the mean height from the CEJ was $24.1 \pm 4.6,21.1 \pm 4.8$, and $22.4 \pm 3.7 \mathrm{~mm}$ in the second premolar, first molar, and second molar, respectively [10]. These results were much higher than those of the present study. The previous study had a reference point on the CEJ of the tooth, while the

Table 4 Canal height according to gender, edentulism, and right/left (mean $\pm \mathrm{SD}, \mathrm{mm}$ )

\begin{tabular}{|c|c|c|c|c|c|c|}
\hline & \multicolumn{2}{|l|}{ Gender } & \multicolumn{2}{|c|}{ Edentulism } & \multicolumn{2}{|c|}{ Right/left } \\
\hline & Female & Male & Full & Partial & Right & Left \\
\hline $\begin{array}{l}\text { Identified/ } \\
\text { investigated }\end{array}$ & $31 / 109$ & $61 / 175$ & $18 / 60$ & $74 / 224$ & $45 / 138$ & $47 / 146$ \\
\hline $\mathrm{CH}$ & $\begin{array}{l}16.88 \\
( \pm 3.67)\end{array}$ & $\begin{array}{l}16.18 \\
( \pm 2.85)\end{array}$ & $\begin{array}{l}16.76 \\
( \pm 3.41)\end{array}$ & $\begin{array}{l}16.36 \\
( \pm 3.10)\end{array}$ & $\begin{array}{l}16.85 \\
( \pm 3.04)\end{array}$ & $\begin{array}{l}16.25 \\
( \pm 3.49)\end{array}$ \\
\hline
\end{tabular}


Table 5 Distribution of canal height (mean \pm SD, $\mathrm{mm}$ )

\begin{tabular}{lllllllll}
\hline $\mathrm{CH}$ & $<11$ & $<13$ & $<15$ & $<17$ & $<19$ & $<21$ & $21 \leq$ & $\mathrm{Sum}$ \\
\hline$N$ (number) & 2 & 9 & 17 & 31 & 18 & 9 & 6 & 92 \\
$N(\%)$ & 2.2 & 9.8 & 18.5 & 33.7 & 19.6 & 9.8 & 6.4 & 100 \\
\hline
\end{tabular}

present study set a reference point on the alveolar crest of edentulous region. Alveolar bone resorption after extraction could be an explanation of the presently higher results. In the present study, as well as in anatomic studies $[7,9,10,14]$ and a radiographic study [13], the intraosseous loop formed a concave arch, with the first molar area being the lowest point of the bony canal arch course. During surgical procedures including lateral window osteotomy, more precautions should be taken at the first molar region than at the premolar region.

The most frequent horizontal position of the canal in the lateral wall was intraosseous or intrawall type (G2), $77.27 \%$ in the first molar and $87.21 \%$ in the second molar region. The results corresponded with another radiographic study [15], but in Korean cadavers, the canals were observed in G1 position most frequently [10].

Hur et al. [10] and Elian et al. [12] recommended designing the superior osteotomy line 13 to $15 \mathrm{~mm}$ from the alveolar crest for placing proper length of dental implant $[10,12]$. In this study, a $\mathrm{CH}$ exceeding $13 \mathrm{~mm}$ was evident in $88 \%$ of CT scans. This result indicates that $12 \%$ of the cases could be followed by surgical vascular complications.

Even though the intraosseous loop was radiographically evident in only $32 \%$ in this study, the results could be used to prevent the arterial bleeding at the time of lateral window surgery, especially under local anesthesia.

\section{Conclusions}

In the horizontal positions of the bony canals, the intraosseous type was most predominant. $\mathrm{CHs}$ more than $15 \mathrm{~mm}$ and less than $17 \mathrm{~mm}$ were most prevalent (33.7 \%) and those under $13 \mathrm{~mm}$ were $12.0 \%$. The radiographic findings in this study could be used to decide the lateral osteotomy line avoiding potential vascular complication. However, since only one third of the canals could be detected in CT scans, precautions should be taken for the possibility of severe bleeding during osteotomy.

\section{Competing interests}

In consideration of publication of my contribution in Maxillofacial Plastic and Reconstructive Surgery, none of the authors have any competing interests in the manuscript.

\section{Authors' contributions}

$K$ and $P$ designed and supervised this study, participated in the sequence alignment. $L$ carries out radiographic measurements, statistic analysis and drafted the manuscript. $M$ reviewed statistic analysis and data alignments. All authors read and approved the final manuscript.

\section{Author details}

'Department of Oral and Maxillofacial Surgery, College of Dentistry Jukjeon Dental Hospital, Dankook University, Yongin, South Korea. ${ }^{2}$ Department of Oral and Maxillofacial Surgery, Kunkuk University Medical Center, Seoul, South Korea. ${ }^{3}$ Department of Conservative Dentistry, College of Dentistry Daejeon Dental Hospital, Wonkwang University, Deajeon, South Korea. ${ }^{4}$ Department of Periodontology, Graduate School of Medicine, Ewha Womans University, 1071, Anyangcheon-ro, Yangcheon-gu, Seoul 158-710, South Korea.

Received: 18 August 2015 Accepted: 16 November 2015

Published online: 04 January 2016

\section{References}

1. Wallace SS, Froum SJ (2003) Effect of maxillary sinus augmentation on the survival of endosseous dental implants. A systematic review. Ann Periodontol 8:328-43

2. Del Fabbro M, Testori T, Francetti L, Weinstein R (2004) Systematic review of survival rates for implants placed in the grafted maxillary sinus. Int J Periodontics Restorative Dent 24:565-77

3. Schwartz-Arad D, Herzberg R, Dolev E (2004) The prevalence of surgical complications of the sinus graft procedure and their impact on implant survival. J Periodontol 75:511-6

4. Chanavaz M (1996) Sinus grafting related to implantology. Statistical analysis of 15 years of surgical experience (1979-1994). J Oral Implantol 22:119-30

5. Zijderveld SA, van den Bergh JP, Schulten EA, ten Bruggenkate CM (2008) Anatomical and surgical findings and complications in 100 consecutive maxillary sinus floor elevation procedures. J Oral Maxillofac Surg 66:1426-38

6. van den Bergh JP, ten Bruggenkate CM, Disch FJ, Tuinzing DB (2000) Anatomical aspect of sinus floor elevations. Clin Oral Implants Res 11:256-65

7. Traxler H, Windisch A, Geyerhofer U, Surd R, Solar P, Firbas W (1999) Arterial blood supply of the maxillary sinus. Clin Anat 12:417-21

8. Allen WE 3rd, Kier EL, Rothman SL (1973) The maxillary artery: normal arteriographic anatomy. Am J Roentgenol Radium Ther Nucl Med 118:517-27

9. Solar P, Geyerhofer U, Traxler H, Windisch A, Ulm C, Watzek G (1999) Bloody supply to the maxillary sinus relevant to sinus floor elevation procedure. Clin Oral Implants Res 10:34-44

10. Hur MS, Kim JK, Hu KS, Bae HE, Park HS, Kim HJ (2009) Clinical implications of the topography and distribution of the posterior superior alveolar artery. J Craniofac Surg 20:551-4

11. Standring S (2005) Gray's anatomy, 39th edn. Churchill Livingstone, London, pp 572-9

12. Elian N, Wallace S, Cho SC, Jalbout ZN, Froum S (2005) Distribution of the maxillary artery as it relates to sinus floor augmentation. Int J Oral Maxillofac Implants 20:784-7

13. Mardinger O, Abba M, Hirshberg A, Schwartz-Arad D (2007) Prevalence, diameter and course of the maxillary intraosseous vascular canal with relation to sinus augmentation procedure: a radiographic study. Int J Oral Maxillofac Surg 36:735-8

14. Rosano G, Taschieri S, Gaudy JF, Del Fabbro M (2009) Maxillary sinus vascularization: a cadaveric study. J Craniofac Surg 20:940-3

15. Ella B, Sédarat C, Noble Rda C, Normand E, Lauverjat Y, Siberchicot F et al (2008) Vascular connections of the lateral wall of the sinus: surgical effect in sinus augmentation. Int J Oral Maxillofac Implants 23:1047-52

\section{Submit your manuscript to a SpringerOpen ${ }^{\circ}$ journal and benefit from:}

- Convenient online submission

- Rigorous peer review

- Immediate publication on acceptance

- Open access: articles freely available online

- High visibility within the field

- Retaining the copyright to your article

Submit your next manuscript at $>$ springeropen.com 